E International

\title{
Integration for Seamless Transport
}

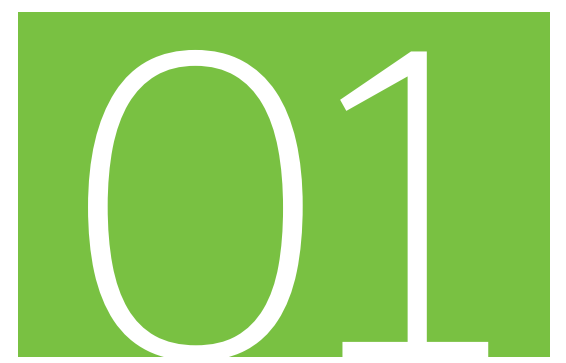

Discussion Paper 2012 01

John Preston 
This document was produced as a Background Paper for the 2012 Summit of the International Transport Forum, on Seamless Transport: Making Connections, held from 2-4 May 2012 in Leipzig, Germany. The views expressed in this document do not necessarily reflect those of the member countries of the International Transport Forum.

Further information about the International Transport Forum is available at www.internationaltransportforum.org 


\title{
INTEGRATION FOR SEAMLESS TRANSPORT
}

Discussion Paper No. 2012-01

\author{
John PRESTON \\ University of Southampton, \\ United Kingdom \\ jpreston@soton.ac.uk
}

April 2012 


\section{INTERNATIONAL TRANSPORT FORUM}

The International Transport Forum at the OECD is an intergovernmental organisation with 53 member countries. It acts as a strategic think tank with the objective of helping shape the transport policy agenda on a global level and ensuring that it contributes to economic growth, environmental protection, social inclusion and the preservation of human life and well-being. The International Transport Forum organizes an annual summit of Ministers along with leading representatives from industry, civil society and academia.

The International Transport Forum was created under a Declaration issued by the Council of Ministers of the ECMT (European Conference of Ministers of Transport) at its Ministerial Session in May 2006 under the legal authority of the Protocol of the ECMT, signed in Brussels on 17 October 1953, and legal instruments of the OECD.

The members of the Forum are: Albania, Armenia, Australia, Austria, Azerbaijan, Belarus, Belgium, Bosnia-Herzegovina, Bulgaria, Canada, China, Croatia, the Czech Republic, Denmark, Estonia, Finland, France, FYROM, Georgia, Germany, Greece, Hungary, Iceland, India, Ireland, Italy, Japan, Korea, Latvia, Liechtenstein, Lithuania, Luxembourg, Malta, Mexico, Moldova, Montenegro, Netherlands, New Zealand, Norway, Poland, Portugal, Romania, Russia, Serbia, Slovakia, Slovenia, Spain, Sweden, Switzerland, Turkey, Ukraine, the United Kingdom and the United States.

The International Transport Forum's Research Centre gathers statistics and conducts co-operative research programmes addressing all modes of transport. Its findings are widely disseminated and support policymaking in member countries as well as contributing to the annual Summit.

\section{DISCUSSION PAPERS}

The International Transport Forum's Discussion Paper Series makes economic research, commissioned or carried out at its Research Centre, available to researchers and practitioners. The aim is to contribute to the understanding of the transport sector and to provide inputs to transport policy design. The Discussion Papers are not edited by the International Transport Forum and they reflect the author's opinions alone.

The Discussion Papers can be downloaded from:

www.internationaltransportforum.org/jtrc/DiscussionPapers/jtrcpapers.html

The International Transport Forum's website is at: www.internationaltransportforum.org or for further information on the Discussion Papers, please email: itf.contact@oecd.org 


\section{TABLE OF CONTENTS}

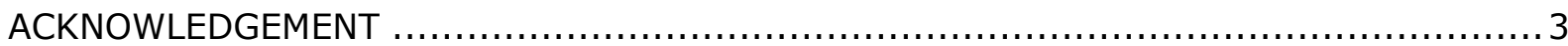

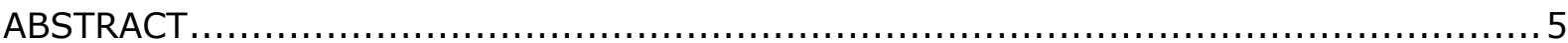

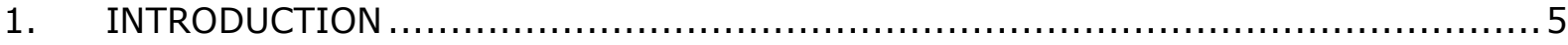

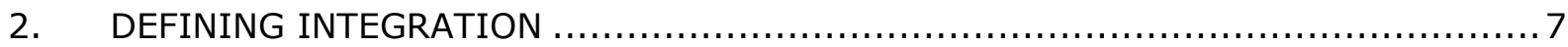

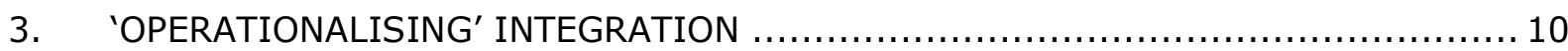

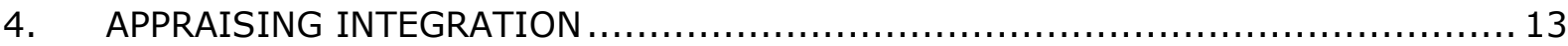

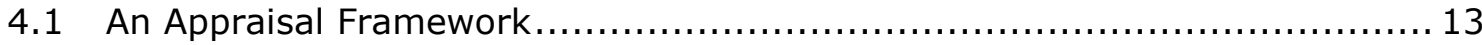

4.2 Evidence Base on the Costs and Benefits of Transport Integration ............ 14

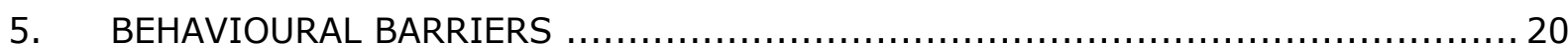

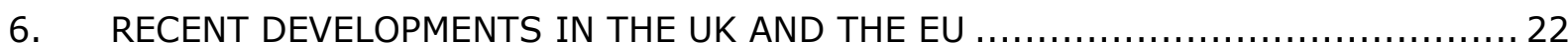

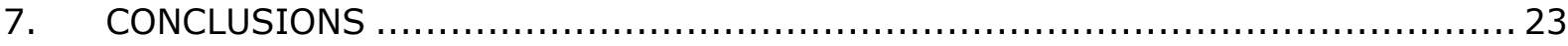

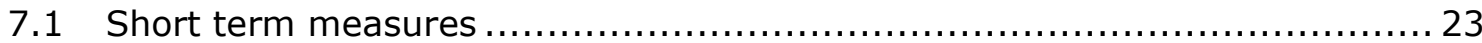

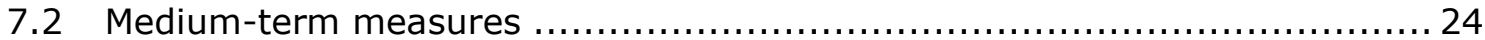

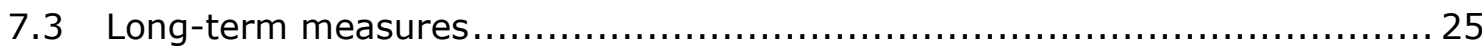

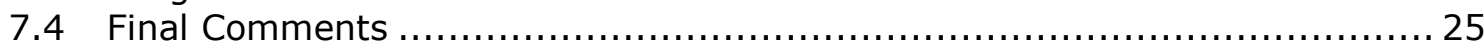

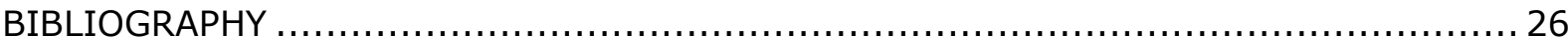

Southampton, April 2012

\section{ACKNOWLEDGEMENT}

This work was initially based on research two research projects undertaken for the Centre for Cities and the Institution of Civil Engineers in the summer of 2008, and updated in work for the International Transport Forum in the spring of 2012. However, the conclusions are solely those of the author. 



\begin{abstract}
The concept of integrated and seamless transport has wide political support but framing effective policies that deliver the desired outcome has proved difficult. This paper builds on and updates earlier work by the author that attempted to analyse the reasons for the relative failure of integrated transport polices with particular reference to experience in the UK. Four main factors are highlighted. The first relates to the difficulties that have been faced in defining the integration concept. It is argued that a ladder of integration can be a useful tool in framing policy. The second relates to difficulties in 'operationalizing' the concept and here it is suggested that a ladder of interventions may also be a useful tool. The third is that there has been a lack of practical evidence on the success of integrated policies but it is argued that this evidence base is now emerging. The fourth has been the barriers to behavioural change that integration requires, both for individuals and institutions. Here advances in economic, social and psychological models of behaviour are giving new insights into how these barriers may be overcome. The prospects for the delivery of more integrated and seamless transport, in both the UK and the European Union, are reviewed with reference to recent policy White Papers.
\end{abstract}

\title{
1. INTRODUCTION
}

The concept of integrated transport has a long pedigree. Its origins at a national scale in the United Kingdom (UK) can be traced back at least to the 1947 Transport Act and the creation of the British Transport Commission (BTC) with the objective to secure the provision of an efficient, adequate, economical and properly integrated system of public inland transport and port facilities (Button, 1993, 249). The subsequent fortunes of integrated transport were initially related to political control. Conservative administrations tended to have little support for the concept - the BTC being abolished by the Macmillan administration's 1962 Transport Act. By contrast, Labour administrations tended to embrace the concept. The Wilson government's 1968 Transport Act established Passenger Transport Authorities (PTAs) and for a time there appeared to be cross-party support with the Heath government's 1972 Local Government Act extending the role of PTAs. Such consensus disappeared for a time with the Thatcher administrations from 1979 to 1990, with the emphasis on deregulation and privatisation. However, there were some signs of a consensus re-emerging in the Major administration (1990-97), with the Green Paper, Transport: The Way Forward, acting as a pre-cursor to subsequent transport policy developments (Cm 3234, 1996)

Integration made a big comeback with the new Labour administration of 1997 and the 1998 Transport White Paper - A New Deal for Transport: Better for Everyone issued 
by the Department for the Environment, Transport and the Regions (DETR, 1998), although the more detailed delivery plan had to wait two years until the publication of the Ten Year Plan (DETR, 2000a). However, a series of events occurred that were to effectively scupper the Ten Year Plan and the integrated transport policy that underpinned it. The fuel protests of September 2000 illustrated the power of the road lobby and the unpopularity of fuel taxation. The Hatfield rail accident of October 2000 led to a sequence of events that undermined rail finances leading to Railtrack being placed in administration in October 2001 and being replaced by Network Rail in October 2002. By early 2003, the Ten Year Plan was effectively dead to be replaced by another Transport White Paper in 2004. As a result most commentators would agree that New Labour's Integrated Transport agenda largely failed (Docherty and Shaw, 2003, 2008). However, it remains an important policy motif under the Conservative Liberal Democrat Coalition Government elected in May 2010, as reflected by the 2011 Local Transport White Paper of the Department for Transport (DfT, 2011a), albeit with different nomenclature, with an emphasis on sustainability rather than integration.

Policy developments in the UK are mirrored by those in the European Union where the 1957 Treaty of Rome, articles 74-79, provided for a Common Transport Policy (CTP). However, progress was slow until 1985 when the European Court of Justice declared that the inland transport of passengers and freight should be open to all Community firms, without discrimination as to nationality or place of establishment. In the same year, the European Commission's White Paper on the completion of the internal market (and the subsequent 1986 Single European Market Act) placed transport at the forefront of moves towards the completion of the single market (CEC, 1985). In 1992 the Commission published a White Paper on the CTP (EC, 1992), which was adopted by the Transport Council in June 1993. The White Paper marked an important change in emphasis for the CTP. Previously the CTP had been aimed at the completion of the internal market by the elimination of artificial regulatory barriers. It now provided a more comprehensive policy designed to ensure the proper functioning of the Community's transport systems which was described as 'sustainable mobility'. It also addressed the integration of environmental objectives as laid down in the Maastricht Treaty (which was finally ratified in 1993). A further White Paper was published in 2001 with the central aim being to achieve modal shift through a more integrated transport system (CEC, 2001). However, there has been little subsequent evidence of modal shift being achieved - although the mid-term review persevered with the concept of sustainable mobility (CEC, 2006) and the latest White Paper continues to embrace integration (EC, 2011).

Most people (although not all - for a dissenting voice see Hibbs, 2000) would support the notion of an integrated transport system. Drawing on and expanding earlier work by the author (Preston, 2010a, 2010b), this paper explores why integration has proved so difficult to achieve in practice and attempts to suggest some remedial measures. Four issues are highlighted. The first is the failure to define the concept - this is examined in section 2. The second is the failure to operationalise the concept - this is examined in section 3. The third is the lack of an evidence base on the success of integrated transport policies. The beginnings of such an evidence base are presented in section 4 . The fourth relates to the barriers, for both individuals and institutions, to the behavioural change required for transport integration. Some of the economic, social and psychological models that might explain these barriers and identify tools to overcome them are discussed in section 5. Recent developments with respect to integration are reviewed with respect to the United Kingdom and the European Union in section 6, before some general conclusions are drawn in section 7. 


\section{DEFINING INTEGRATION}

Integration is a multi-faceted concept that includes a number of factors and a multiplicity of definitions (Potter, 2010, Givoni and Banister, 2010, 5-7). This has led to some to dismiss it as an obfuscatory device (Glaister, 2002). Others have embraced its complexity by describing integrated transport as a scalar (Potter and Skinner, 2000) or by referring to the rungs of an integration ladder (Hull, 2005). For transport these rungs might include, in approximate ascending order of organisational difficulty (see also Figure 1, which highlights some examples of UK best practice):

i. the integration of public transport information.

ii. the physical integration of public transport services

iii. the integration of public transport fares and ticketing.

iv. the integration of infrastructure provision, management and pricing for public and private transport.

v. the integration of passenger and freight transport

vi. the integration of (transport) authorities.

vii. the integration between transport measures and land use planning polices.

viii. integration between general transport policies and the transport policies of the education, healthcare and social services sectors.

ix. the integration between transport policies and policies for the environment and for socio-economic development.

These rungs might be distinguished between horizontal integration (which brings together different aspects of the transport system - steps i to iv) and vertical integration (which brings together transport with other aspects of governance - steps $v$ to vii). Sustainability might be thought of as being the highest rung of the integration ladder (see George, 2001) and this notion is consistent with the change in nomenclature in the UK (DfT, 2009a, 2011a).

In practice, the definition of integrated transport varies depending on disciplinary/theoretical perspectives, for example between engineering, microeconomics, management and political science viewpoints (NEA et al., 2003). Stylised counterpoints are provided by the engineering and microeconomics perspectives. The engineering viewpoint, which is also shared by architects, planners and urban designers, is that certain aspects of integration can be based on best practice - see, for example, Creswell, 1979 , or Rogers, 1999. This best practice can be determined from the use of analytics to optimise network design (for example, van Nes, 2002). 
Figure 1. The Integration Ladder

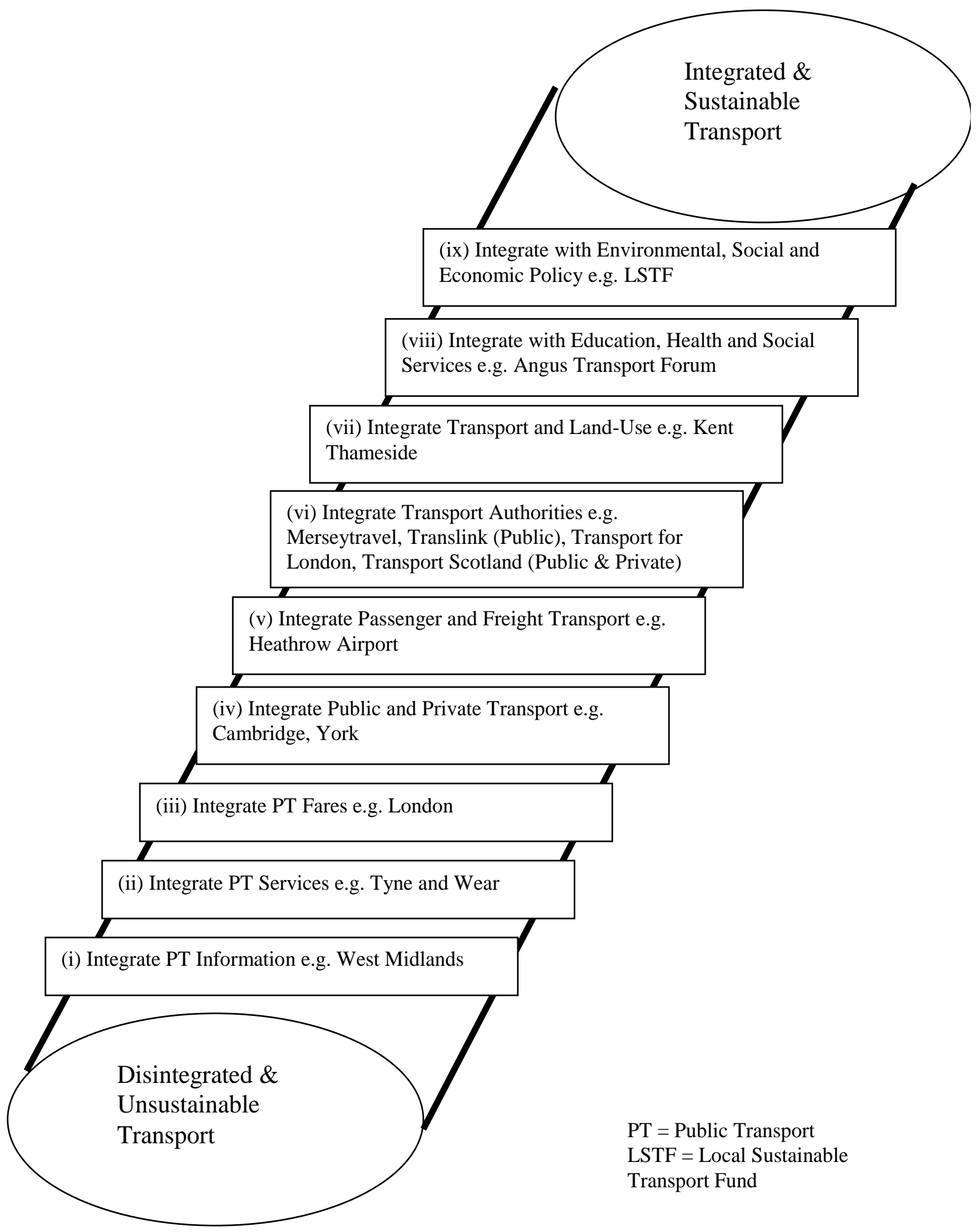


The microeconomics perspective sees integration as a response to market failure. It is the view of integration that has predominated in the UK, but with two distinct perspectives. A neo-classical perspective is that co-ordination will be provided by competition. If consumers value integration, the free market will provide it (Hibbs, op cit.). This was essentially the neo-liberal line adopted by the Thatcher administrations, albeit one modified by the dual emergence of the sustainability paradigm following the Brundtland Report in 1987 and of a green economics that could offer market related solutions to environmental problems such as traffic pollution (Pearce et al., 1989).

A more Keynesian perspective highlights that transport exhibits a number of market failures of which the most important are wasteful competition, network failures and the presence of externalities (particularly related to congestion). With respect to wasteful competition it is argued that because transport operators have some monopoly in both space and time, deregulated markets will exhibit features of monopolistic (taxis) or oligopolistic (buses and trains) competition resulting in too much service being supplied at too high fares (Evans, 1987, Preston et al., 1999). In extreme cases, deregulated public transport markets can be characterised by oligopoly or even monopoly - with too little service at too high fares. This was largely the argument used to regulate road transport in the 1930s and to bring public transport under public control, particularly in the major cities. For public transport, there are benefits from having a network of services. The more users there are, the lower the time costs - as more frequent services will mean lower waiting times, more routes will mean lower walking time and the greater scope for mixing stopping and express services will lead to lower in-vehicle time. This is referred to as the Mohring effect (Mohring, 1972) and provides 'first-best' arguments for an integrated public transport system that has lower fares, higher frequencies, smaller vehicles and higher levels of subsidy than has been the norm in Britain (see, for example, Nash, 1988). It partly provided the justification for the subsidisation of public transport that became institutionalised with the 1968 Transport Act. More recently, externalities have come to the fore. The Ten Year Plan's focus was on the extent to which integrated transport could reduce road congestion (DETR, 2000a) but subsequently more emphasis has been placed on global and local environmental impacts and in particular the reductions in carbon emissions given the ambitious targets set by the UK's 2008 Climate Change Act (an 80\% reduction in the net carbon account between 1990 and 2050).

Theoretical analysis suggests transport integration will not occur autonomously as free market provision is likely to be affected by service instabilities and schedule matching (van Reeven, 2003) and, with multiple operators across a number of jurisdictions, integration of fares, services and information is unlikely to occur (Roumboutsos and Kapros, 2008). Integrated transport requires public intervention. The conventional approach is through public ownership and control of transport infrastructure and operations - an approach associated with state socialism, although not exclusively so. The alternative is through the social regulation of markets - essentially the Third Way adopted by new Labour and associated with Giddens (2000).

For the purposes of this paper we adopt a microeconomic perspective by defining transport integration as: the organisational process through which the planning and delivery of elements of the transport system are brought together, across modes, sectors, operators and institutions, with the aim of increasing net social benefits (NEA et al, 2003, p17). However, it should be emphasised that, following Pearce et al.(1989) we are using the term net social benefits in its widest sense so that it includes environmental 
impacts, as well as social and economic, thus overcoming the objection of Anderton, 2010 that the definition neglects environmental concerns.

\section{3. 'OPERATIONALISING' INTEGRATION}

In general, progress with integration has been limited. In part, this reflects the fact that the car can, in many instances, provide a seamless journey, in marked contrast to public transport alternatives. Givoni and Banister (2010) note that progress has been made in some sectors of the transport market, particularly where they are aligned with commercial objectives. For example, supply chain management techniques have helped integrate elements of the freight transport market (Allen et al., 2010), whilst some airports have developed as intermodal and interconnected hubs. For example, at London Heathrow the airport operator has provided an express rail link to central London and a personal rapid transit system to one of the business car parks. For local passenger transport some progress has been made in the UK at the lower and intermediate rungs of the integration ladder, but this has been uneven. For example, devolution has proved a fillip to integration, as it has produced institutions such as Transport Scotland and Transport for London with a clear spatial focus (MacKinnon et al., 2008). Devolved transport authorities are able to set a clear rationale for their policies - e.g. economic development in Scotland and behaviour change in London.

For other steps of the integration ladder, there have been difficulties in delivering integration. The reasons for this are manifold but many of them are institutional in nature. Outside London, there is limited public control of the bus industry and, despite the fact that the transport ministry (DfT) retains strong oversight of private rail operators, local authorities have little input on rail services except in the devolved administrations (which for national rail includes London, Scotland and Merseyside). PTAs in the major conurbations lost their co-signatory status on rail franchises in 2005. Some PTAs have had some successes. Centro (West Midlands) provides high quality integrated information. Nexus (Tyne and Wear) has been able to integrate bus services with its Metro rail services at some of its interchanges (e.g. Heworth) but not at others (e.g. Gateshead). The 2008 Local Transport Act has reformulated PTAs to become Integrated Transport Authorities (ITAs) with some increased powers and possible extensions in jurisdictions, but there were concerns over the extent to which these powers would be taken up (Preston and Spear, 2008) which seem to have been justified by the limited subsequent developments.

Local Authorities have limited financial powers and have to apply for Treasury (the UK's Ministry of Finance) approval for all major highway and public transport schemes above a threshold of $£ 5$ million, effectively preventing them from taking their own transport investment decisions. Partly as a result, commentators have noted that delivery of Local Transport Plans is limited compared to better funded alternatives such Plans de Déplacements Urbains in France (Rye, 2008).

Although local transport authorities can specify socially necessary bus services, these are typically less than $20 \%$ of total vehicle miles. More importantly, councils have little 
power to determine fares, service levels or service quality on the commercial bus network. They are also required to demonstrate that the support they give to 'social' services does not negatively impact on the commercial network. Evidence from Merseyside (Huang and Preston, 2004) suggested that appropriately specified Quality Contracts in the city-region would lead to net economic benefits of around $£ 13$ million per annum. Other research suggests that in areas where the market is monopolised such as the West Midlands and West Yorkshire - reductions in bus fares and increases in service levels would be economically beneficial (Glaister, 2001).

A further barrier to integration is the fragmented ownership of public transport. The more positive examples of transport integration - such as Brighton and Cambridge tend to occur in areas where there is a dominant operator and good working relationships with local authorities, often forged at an individual level. Some successes have also been achieved in cities where there are two evenly matched and innovative bus companies as in Edinburgh (First and Lothian Regional Transport), Nottingham (Nottingham City Transport and Trent Barton) and Oxford (Go-Ahead and Stagecoach).

However, partnership working in many areas has been hampered by the limited ability of local authorities to deliver bus priority measures. In Greater Manchester, the PTA was responsible for planning public transport, while responsibility for roads rested with individual local authorities. This situation has only been partially resolved by the creation of ITAs. Non metropolitan two-tiered authorities face a similar situation - with public transport and roads controlled by the County, but parking and traffic policies largely controlled by the Districts.

Local Authorities lack a financial incentive to provide bus priority infrastructure and operators are reluctant to enter into any profit sharing type arrangement to help finance such infrastructure (Preston, 2007). Hence, there have only been a few Statutory Quality Bus Partnerships (in Dundee, Sheffield and Nottingham) established since the passage of the 2000 Transport Act. Despite the encouragement given by the 2005 Transport Act there have yet to be any Quality Contracts, although the threat does seem to have stimulated Quality Partnerships (van de Velde and Preston, 2012).

There have been some successes further up the integration ladder. For example, transport and land-use has been integrated around the Fastrack bus rapid transit system in the regeneration of Kent Thameside, whilst conventional public transport and unconventional transport (such as Demand Responsive Transit) have been integrated in Angus, rural Scotland. At the highest level, central Government is placing an emphasis on the Local Sustainable Transport Fund.

However, there have also been failures, particularly at the upper rungs of the integration ladder. At the national level, the Department of Environment, Transport and the Regions (DETR) super ministry was short lived (1997-2001) and key policies such as the Ten Year Plan and the Multi Modal Studies failed to deliver (Docherty and Shaw, 2003). At lower levels of government, Regional Transport Strategies failed to gain any traction outside of the devolved administration and have been abandoned by the Coalition Government, whilst Local Areas Agreements and Multi Agency Agreements have struggled to provide joined-up government. A comparison of integration practices in Malmo, Sweden, with those in Bristol and Newcastle found a series of implementation failures in Britain, including duplication of procedures, failures in communication and the lack of clear and resourced responsibilities (Hull, 2005). The British planning process is costly in terms of time and money, due to the large number of organisations involved 
and despite ways to streamline it put forward by the Barker Review of Land Use Planning in 2006. Particular problems exist in integrating transport and land-use at both the local (Wootton and Marsden, 2001) and regional (MVA, 2004) levels. Delivering the solutions put forward by multi-modal studies required for major projects under transport investment appraisal guidelines (DETR, 2000b) has floundered on the fact that delivery agencies are structured on modal lines, particularly the Highways Agency and DfT Rail (previously by the Strategic Rail Authority), and as a result, measures that should have integrated transport became fragmented (Goodwin, 2003).

A complicating issue has been the wide range of interventions that might be considered in delivering integrated transport. Various taxonomies of these interventions have been postulated. The European Commission often distinguished between physical (e.g. infrastructure provision), economic (e.g. pricing) and regulatory measures. May (2001) distinguishes between infrastructure provision, infrastructure management, information provision, land use planning, pricing and marketing (attitudinal and behavioural) measures.

The recent Transport White Paper in the UK highlights a ladder of interventions (DfT, 2011a, 13). This draws on evidence from public health evaluations (which itself is suggestive of a form of policy integration) and the concept of choice architectures and nudges (Thaler and Sunstein, 2009) and is illustrated by Figure 2.

Figure 2. Ladder of Interventions

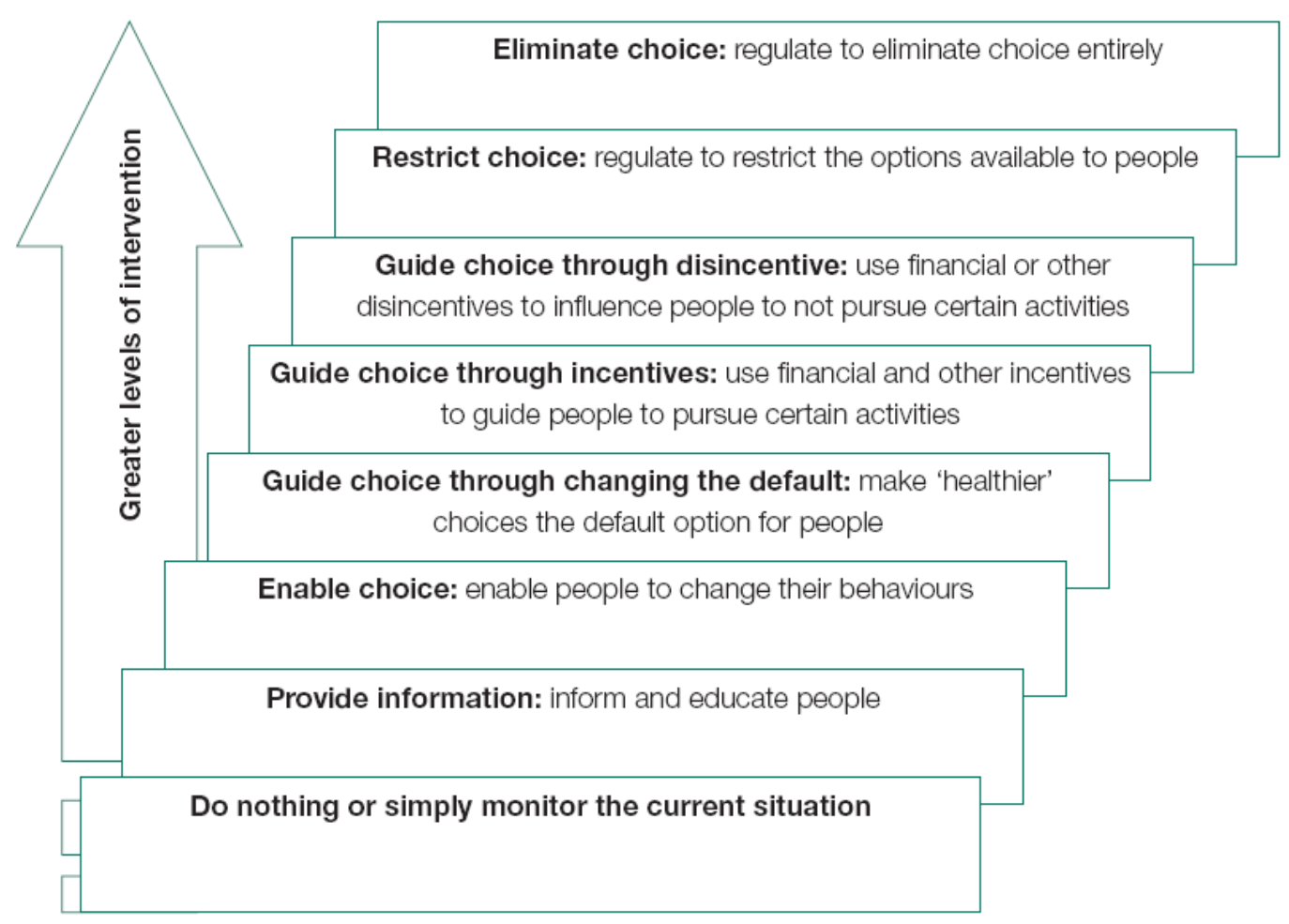

Source: DfT, 2011 a. 
In contrast to the ladder of integration, the greatest emphasis has traditionally been on the higher rungs of the intervention ladder. Regulation either eliminates choice (for example by preventing new entry to transport markets) or restricts (for example by vehicle bans). Financial interventions (such as taxes) are usually used as disincentives but can be reframed to act as incentives (such as differentiated taxes to encourage greener vehicles). Less emphasis has been placed on trying to change the default option, enabling choice and on providing information and education, although this balance is changing.

\section{APPRAISING INTEGRATION}

There is a need to establish an evidence base on the effectiveness of integrated transport policies. Given our microeconomic definition, this will require an appraisal framework to determine net changes in social benefits. This is briefly provided in the next sub-section before moving on to consider some relevant evidence.

\subsection{An Appraisal Framework}

An appropriate framework for appraising (ex-ante) and evaluating (ex-post) integrated transport is provided by the UK's New Approach to Appraisal (NATA) and the accompanying web-based transport analysis guidance ${ }^{1}$. The thrust of this approach is that transport interventions are measured against five key criteria: Economy, Accessibility, Safety, Integration and Environment (sometimes referred to as the EASIE criteria). These are then split into a number of sub-objectives and the results displayed in an appraisal summary table (AST). NATA is in essence a combination of Cost-Benefit Analysis and Environmental Impact Assessment.

A key measure in the NATA is the Benefit Cost Ratio (BCR) which is simply the Present Value of Benefits (PVB) divided by the Present Value of Costs (PVC). Where there are no budget constraints, schemes with a BCR greater than 1 should taken forward, as they have a net social benefit. However, in reality there are budget constraints and transport must compete with other sectors for government funding. As a result the DfT initially suggested a threshold of 1.5 for medium value for money and 2 for high value for money, although subsequently an additional threshold of 4 was introduced to denote very high value for money (DfT, 2009b). This change reflects tightening budget constraints.

${ }^{1}$ www.webtag.org.uk Note that NATA has been subsumed into a wider business case approach that, alongside the economic case, also considers strategic, financial, management and commercial aspects (DfT, 2011b). 


\subsection{Evidence Base on the Costs and Benefits of Transport Integration}

An evidence base on the cost and benefits of integration is needed, or at least on the costs and benefits of interventions other than road building and enhancements. This section builds on earlier work by the author (Preston, 2010b).

\subsubsection{The Eddington Transport Study}

A useful evidence base is that put together for the Eddington Transport Study (Eddington, 2006, Dodgson, 2009), although a major constraint is that this study tended to examine individual measures rather than packages of measures. Given that improving public transport constitutes the first steps of the integration ladder, Table 1 summarises the appraisal of over 30 public transport schemes, with mean BCRs in the range 2.1 to 2.6, although there are a number of schemes that have BCRs below 1.5. For most of these schemes by far the biggest element of benefit is the time saving to users, although for schemes with dedicated rights of way, time savings to non-users are also important. Non monetised impacts tend to be small but in general positive. Table 1 also includes three local road schemes that include public transport (such as bus priority and bus based park and ride) and other elements (such as pro walking and cycling measures) and are described as integrated transport schemes. These schemes seem to have relatively high BCRs (mean 4.97) and are worthy of further investigation.

Table 1. Eddington Evidence on Public Transport Integration BCRs.

\begin{tabular}{|c|c|c|c|c|}
\hline Type & Number & Locations & Mean & Range \\
\hline $\begin{array}{l}\text { Integrated } \\
\text { Transport } \\
\text { Schemes }\end{array}$ & 3 & $\begin{array}{l}\text { Reading, } \\
\text { Scarborough, } \\
\text { w2emms }\end{array}$ & 4.97 & $2.7-7.7$ \\
\hline $\begin{array}{l}\text { Public Transport } \\
\text { Interchanges }\end{array}$ & 6 & $\begin{array}{l}\text { Altrincham, Bradford, } \\
\text { Coleshill, Mansfield, } \\
\text { Warrington, } \\
\text { Wolverhampton }\end{array}$ & 2.57 & $1.0-4.8$ \\
\hline $\begin{array}{l}\text { Light Rapid } \\
\text { Transit }\end{array}$ & 6 & $\begin{array}{l}\text { Coventry, Leeds, } \\
\text { London, Nottingham, } \\
\text { South Hampshire }\end{array}$ & 2.10 & $1.1-3.6$ \\
\hline Urban Rail & 6 & $\begin{array}{l}\text { Glasgow, London, } \\
\text { York }\end{array}$ & 2.16 & $1.1-3.0$ \\
\hline Bus Schemes & 13 & $\begin{array}{l}\text { Bletchley, Bristol, } \\
\text { Cambridge, } \\
\text { Doncaster, Leeds, } \\
\text { Sheffield, Taunton, } \\
\text { Warwick }\end{array}$ & 2.51 & $1.7-4.0$ \\
\hline
\end{tabular}

Source: DfT (2006) Data on investment returns from transport schemes considered by the Eddington study. DfT, London. w2emms = West to East Midlands Multimodal Study. 
Dodgson (2009, Table 2) shows that local road schemes have higher mean BCRs than public transport schemes - computed as 4.23 for a sample of 48 schemes. However, in the case of roads it might be argued that the non-monetised impacts are less favourable. For some schemes, a modified VFM (Value for Money) calculation has been undertaken by the DfT which takes into account these non-monetised impacts and places a scheme in one of four qualitative categories ${ }^{2}$. There were 43 local roads schemes for which both BCR and modified VFM calculations were made. For 39, the BCR and VFM categorisations were the same, for 2 the modified VFM gave a higher category and for 2 BCR gave a higher category. By contrast, both BCR and the modified VFM calculations were made for 16 local public transport schemes. For 11 of these schemes, the categorisations were the same but for 5 cases the modified VFM analysis produced a higher category. This suggests that at the margins the inclusion of non-monetised impacts strengthens the case for local public transport compared to roads. However, given Dodgson estimated the mean BCR of the 25 local public transport schemes he examined as 1.71 compared to 4.23 for local road schemes, there is a large gap to be reconciled. There are other factors that could explain this gap including the treatment of small time savings (which are particularly important for road schemes - if these were treated as zero then BCRs for local road schemes would reduce), the treatment of tax revenues (public transport schemes will attract some motorists leading to a reduction in taxation revenue ${ }^{3}$ ) and missing impacts (most notably related to social inclusion).

\subsubsection{European Evidence}

Table 2 includes some BCRs for public transport integration schemes examined in work for the Directorate General Transport and Energy (DGTREN) of the European Commission (NEA et al., 2003) and updated using material reported in Givoni and Banister (2010). These schemes have been quantified in slightly different and not strictly comparable ways but generally include construction and operating costs, revenues, and time savings. It is apparent that there are relatively few examples where integration benefits are quantified in BCR terms outside the British Isles (only four of the 10 values presented). This reflects the dominance of the micro-economics approach in the British Isles and of engineering approaches to integration in continental Europe.

\footnotetext{
2 Poor, Low, Medium or High.

3 This was treated as increasing the PVC of a scheme in the Eddington BCR calculations. NATA Refresh suggests that this should alternatively be treated as a reduction in the PVB of a scheme. For an illustrative public transport scheme examined by Nash and Preston (1991) the former method gives a BCR of 1.25 and the latter a BCR of 1.34 suggesting the change will tend to benefit public transport schemes.
} 
Table 2: Public Transport Integrations Schemes

\begin{tabular}{|c|c|c|}
\hline Location & Description & BCR \\
\hline Greater Manchester & $\begin{array}{l}\text { Tariff and Information Integration } \\
\text { Local Transport Plan } 2001 / 2 \text { - } \\
2005 / 6 \\
\text { Major Schemes } 2001 / 2-2005 / 6\end{array}$ & $\begin{array}{l}2.53 \\
4.86 \\
3.71\end{array}$ \\
\hline $\begin{array}{l}\text { West Yorkshire (Cottham, } \\
1985 \text { ) }\end{array}$ & Integrated ticketing & 5.40 \\
\hline London & Information integration & 7.67 \\
\hline Dublin & Area Wide Integration & 2.75 \\
\hline Bucharest & Network integration & 2.90 \\
\hline Rotterdam & $\begin{array}{l}\text { Bus integration with Metro } \\
\text { extension }\end{array}$ & 4.10 \\
\hline $\begin{array}{l}\text { Netherlands (Koopmans, } \\
2006 \text { in Bakker et al., } \\
\text { 2010) }\end{array}$ & $\begin{array}{l}\text { Electronic Ticketing and Access } \\
\text { Gates }\end{array}$ & 4.34 \\
\hline $\begin{array}{l}\text { Paris (Margail and } \\
\text { Auzanett, } 1996 \text { in Bakker } \\
\text { et al., 2010) }\end{array}$ & Park and Ride & $\begin{array}{c}1.36 \text { to } 3.62 \text { Mean } \\
2.49\end{array}$ \\
\hline
\end{tabular}

Sources: NEA et al., 2003; Givoni and Banister, 2010.

It can be seen that all the schemes listed in Table 2 have BCRs in excess of 2 (with a mean of around 4), including network integration in Bucharest, based on a contra-flow bus lane in the city centre, park and ride in Paris and a Metro extension in Rotterdam. Indeed, in the case of the latter this permitted large reductions in bus operating costs and ultimately reductions in bus subsidy which means that this scheme could lead to savings to Government which in turn could result in a negative BCR because it saved Government expenditure and the costs were thus negative (i.e. there was a financial benefit). Other examples of commercial integration include the Jutland Regional and Interregional express bus network in Denmark. This scheme resulted in a $35 \%$ increase in patronage and the whole system was reported as being self-financing, with a cost recovery ratio of $107 \%{ }^{4}$. However, services between the main towns (e.g. Aalborg, Vejle and Viborg) had a cost recovery ratio of $180 \%$, whereas smaller feeder routes only had a cost recovery ratio of $55 \%$. It is unlikely that such cross-subsidy could occur in a deregulated system such as that which exists in Great Britain outside London.

\footnotetext{
${ }^{4}$ Revenue divided by costs
} 
Table 2 also illustrates the benefits of integrated ticketing and information and of area wide integration. The West Yorkshire scheme illustrates the benefits of integrated ticketing using old technology, whilst the Netherlands study indicates further benefits by migrating to newer technology. The Dublin scheme, based on the 2001 Platform for Change document by the Dublin Transportation Office includes a major programme of rail investments including extensions to the suburban rail (DART) network, on-street trams (Luas) and a segregated, higher capacity light rail network (Metro). In Greater Manchester, area wide integration was based largely around Quality Bus Corridors and some extensions to the light rail (Metrolink) system. Appraisal distinguished between Major Schemes (requiring capital support of over $£ 5$ million) and other elements in the Local Transport Plan, a five year planning document introduced by the 2000 Transport Act, which sets out local transport strategies and policies, along with an implementation programme.

It should however be noted that not all economic appraisals are favourable to integrated measures. For example, a study in the Netherlands found that a land-use policy based on managed sprawl (BCR 1.56 to 1.87) was more beneficial than one of increased densification (BCR of 0.08 to 0.67 ), although a number of key benefits could not be monetised (Bakker et al, 2010, 134). The European CIVITAS programmes have undertaken a number of initiatives to develop local sustainable transport but there have been few that have been evaluated through the calculation of a BCR. Piao et al. (2009) found that a lift sharing scheme in Norwich had a BCR of 4.26, whilst a car club in Malmo only had a BCR of 0.65 , reflecting the much higher set-up and administration costs of the latter compared to the former.

\subsubsection{Other Studies}

Further data on the impact of transport integration measures on demand has been collated in work on Smarter Choices (Cairns et al., 2004). Smarter Choices may be seen as a combination of softer measures (such as car and lift sharing), promotion and awareness raising (e.g. personalised and corporate travel planning), sustainable infrastructure (such as new walking and cycling routes) and monitoring and evaluation (IHT, 2009). It has been estimated that a major roll out of these 'soft' measures (referred to as a high intensity scenario) could lead to a $21 \%$ reduction in peak period urban traffic (13\% off-peak) and a reduction in peak period non-urban traffic of $14 \%$ (off-peak $7 \%$ ), resulting in a nationwide reduction in traffic of $11 \%$. By contrast, a low intensity scenario, in which present practice is largely continued, would only lead to a 2$3 \%$ reduction in nationwide traffic, increasing to $5 \%$ for peak period urban traffic. It is estimated that the public expenditure costs of achieving reduced car use by soft measures is around 1.5 pence per kilometre, which suggests a BCR of at least 10 (Cairns et al., 2004,. p v). It should though be noted that it is assumed that these benefits of congestion relief are not dissipated by induced traffic, whilst there is also some concern that the high intensity scenario has failed to take into account the possibility of diminishing marginal returns, although this could be offset by complementarities between measures.

The UK Highways Agency's Influencing Travel Behaviour (ITB) demonstration programme that involved area wide travel plans at three major employment sites (Cambridge Science Park, Northampton General Hospital and Whiteley Business Park), although achieving only modest reductions in car traffic was found to exhibit BCRs in the range of 3.7 to 13 (mean 7.4) (IHT, 2009). Further evidence on smarter choices has come from the Sustainable Travel Towns project. It was found that in the three 
demonstration sites (Darlington, Peterborough and Worcester), between 2004 and 2008, the number of car driver trips per resident decreased by around $9 \%$, compared to a decline of around $1 \%$ in other similar towns (Sloman et al., 2010). The implied BCR in the three towns, accounting only for congestion effects, was estimated to be of the order of 4.5. Including other transport user benefits, health impacts and environmental effects was believed to broadly double this figure. Similar results appear to have been achieved in the London Borough of Sutton where a Smarter Travel programme reduced car's mode share of trips from 58\% to 52\% between 2006 and 2009 (Smarter Travel Sutton, 2010).

Similarly, quality bus partnerships and community rail partnerships may be seen as a form of integration by bringing together operators, authorities and the local community. A review of quality bus partnerships in over 20 locations in Britain indicates short term patronage increases of $18 \%$ (15 months or less) and medium term increases of $36 \%$ (18 months or more) (Sloman, 2003). There is some evidence that Community Rail Partnerships may have a similar demand impacts to Quality Bus Partnerships. For example, the Partnership for the Bittern rail line between Norwich and Sheringham (Norfolk, UK) was reported as increasing patronage by $40 \%$ over five years, with similar effects emerging for the Wherry Lines between Norwich, Great Yarmouth and Lowestoft (Cairns et al., 2004,. p136).

In contrast to these 'soft' measures, there is also a raft of evidence emerging on a particular 'hard' measure in the UK - that of high speed rail. A summary is given by Preston (2012), which shows that the proposals for High Speed 2 (HS2) seem to have acceptable BCRs. In March 2010, the BCR for the London - Birmingham HS2 proposal was estimated at 2.7, including wider economic benefits, although by January 2012, this had been revised to 1.7, largely due to the economic downturn. As a result of network effects, extensions to Leeds and Manchester strengthen the economic case. Physical integration has been given consideration with the inclusion of stops at Old Oak Common (to link with Crossrail) and at Birmingham International (to link with the Motorway network) and the proposed construction of a link to High Speed 1 and the Channel Tunnel. However, the proposed Birmingham terminal is not well linked to the local rail network, access to Heathrow Airport has still to be determined, whilst for the extended network it is proposed to serve some conurbations (notably in South Yorkshire and the East Midlands) by out of town parkways, despite the limited success of such sites in Korea (Bae, 2010) and elsewhere. Planning and assessment of HS2 has included consideration of the use of the classic rail capacity released by the scheme but has not included detailed consideration of fares and ticketing or access/egress services nor of the extent to which HS2 may attract competition. The planning for HS2 has not been integrated with wider transport planning. HS2 will not serve the proposed South Midlands Growth Area, even though the line will pass through it. Moreover, there is some suggestion that upgrading existing road and rail networks can provide higher BCRs than HS2 but these options are not being pursued. The impression that is given is that although some consideration has been given to aspects of integration, planning of HS2 is largely unimodal, as reflected by the creation of High Speed 2 (HS2) Limited in January 2009 as the delivery agency. 
Figure 3. The UK's HS2 High Speed Rail Project

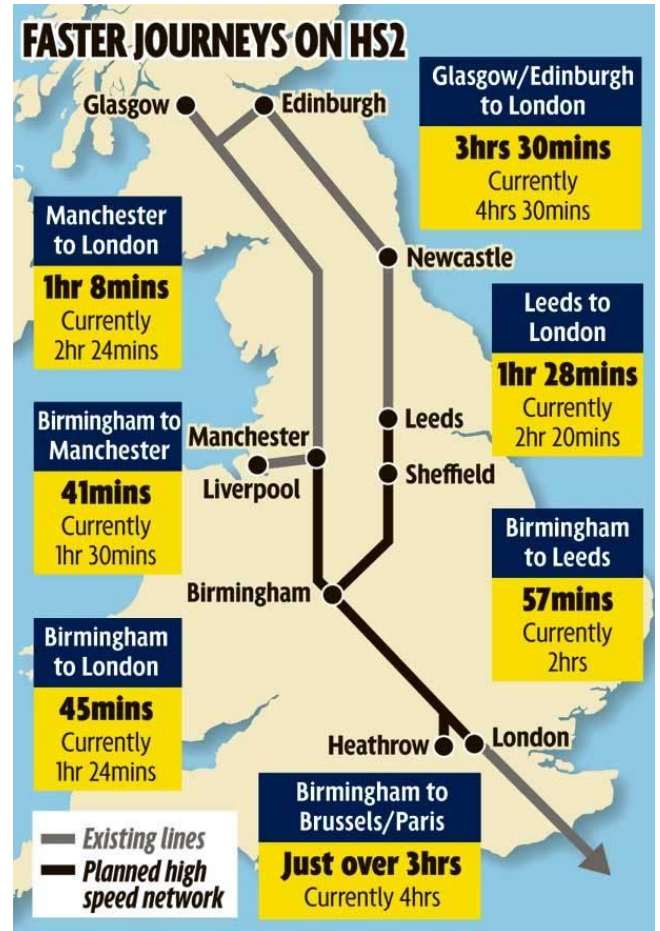

Source: The Daily Mail.

\subsubsection{Evidence on Synergy}

Most of the empirical evidence to date is at the lower rungs of the integration ladder. Insufficient attention has been paid to quantifying synergy - where for example the benefits of two policy measures, such as policy A (road pricing) and policy B (improved public transport) are greater than the sum of the individual components. This might be written as $\operatorname{Ben}(A+B)>\operatorname{Ben}(A)+B e n(B)$ (Mayeres et al, 2003). Those empirical studies that have addressed this issue suggest that this rarely happens in practice but what is more common is either additionality $(\operatorname{Ben}(A+B)=\operatorname{Ben}(A)+\operatorname{Ben}(B))$ or complementarity $(\operatorname{Ben}(A+B)>\operatorname{Ben}(A), \operatorname{Ben}(A+B)>\operatorname{Ben}(B))$ (May et al., 2005a). This means that the benefits of one measure are reinforced by the benefits of another. Furthermore, one measure may reduce the barriers related to another. For example, on its own road pricing may not be politically acceptable because of concern over the adverse impact on low income motorists. However, if combined with public transport improvements particularly targeted to attract low income motorists, these political and distributional constraints may be overcome. Conversely, public transport improvements may not be affordable on their own but may be funded if the revenue from road pricing is hypothecated. May et al. (op cit.) develop an integration matrix that summarises the complementarities between infrastructure, management, pricing, land-use, information and marketing measures. Optimization studies undertaken in Edinburgh suggest that integrated transport might involve road pricing in the peak, public transport service increases, public transport fare reductions and some expansion in road capacity. Similar results have been found for other cities both in the UK (e.g. Leeds) and in continental Europe (e.g. Oslo, Vienna) (May et al., 2005b). Such results have not though normally 
been presented in terms of integrated compared to non integrated transport, although they could be interpreted as such.

\section{BEHAVIOURAL BARRIERS}

The difficulties in operationalizing integration relate to institutional and individual barriers. May and Crass (2007) have identified a range of institutional barriers many of which are apposite to the discussion of UK policy in section 3 above. The barriers include split or duplicated responsibility, inconsistencies in process, political and public acceptability, information and skills shortages, financial constraints and legislative and regulatory requirements. However, section 3 also indicates that some progress has been made in overcoming these institutional barriers.

In many respects, individual barriers have proved more persistent but here too there have been some important developments in our understandings. Useful insights have been provided by the trans-theoretical model of behaviour change that originated with the work of Prochaska and Di Clemente (1983) that posits six stages: pre-contemplation, contemplation, preparation, action, maintenance and termination. A transport variant of such a stages of change model is provided by the TAPESTRY project, albeit one with seven stages (TAPESTRY, 2003). The first stage is an awareness of the problem (precontemplation). This stage was achieved in the UK with the emergence of the new realism in the late 1980s/early 1990s (Goodwin et al., 1991) which recognised that growing congestion, rising environmental degradation and problems of transport-related social exclusion could not be dealt with by road building alone. The second stage accepting responsibility (contemplation) - has been more problematic, despite the best intentions of the 1998 White Paper. At the individual level, surveys indicate strong preference for individualised transport - which has resulted in a high degree of car dependency in the UK and a reluctance to use collective transport due to a variety of reasons including concerns over personal security (Stradling et al., 2000). There is popular support for integrated transport measures but often on the basis that these measures are used by others.

At an institutional level, central government has failed to accept responsibility in some key areas such as charging for road use. This was delegated to local authorities as a result of the 2000 Transport Act but most local authorities have lacked individual or collective policy champions to take charging forward, with the notable exception of London. The green-gold alliance on which Goodwin et al. put much faith, on the basis that there are a number of transport policies that have both economic and environmental gains, has largely failed to materialise. The third and fourth steps - perception and evaluation of the options available - are related to preparation. These are arguably the stages at which the EU and the UK are currently located. However, choices (the fifth step, related to action) have rarely reflected the tenets of integrated transport and as result individual behaviour remains trapped in a high degree of car dependency. Some experimental behaviour (step six, related to maintenance) has been assessed, for example by those involved in personalised travel planning in the Sustainable Travel Towns. Integrated transport policy remains a long way from establishing habitual 
behaviour at a nationwide scale (step seven - termination), at least in the passenger sector. TAPESTRY envisages behavioural changes as a linear process but in reality there will be a degree of circularity punctuated by relapses (see Figure 3). Similarly Smarter Travel Sutton has been influenced by the diffusion of innovation model (and the role of early adopters, late adopters, early majority, late majority and laggards) and the concept of the tipping point (Gladwell, 2000) and the key role of mavens - information specialists who tell others about how a new approach works (Smarter Travel Sutton, 2009).

\section{Figure 3. Behavioural Change Models}
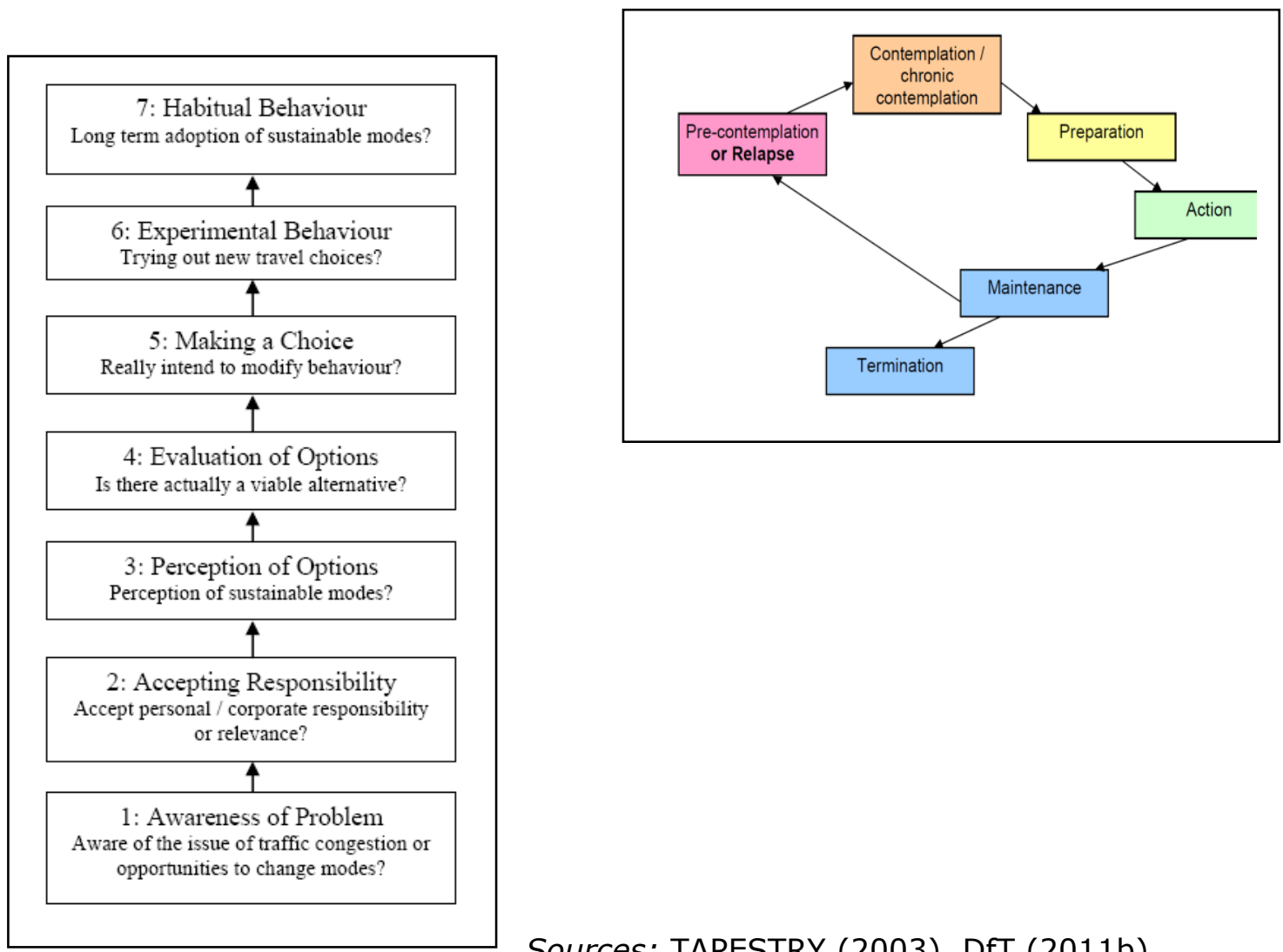

Sources: TAPESTRY (2003), DfT (2011b).

Developments in behavioural insights provided by approaches such as the stages of change model have led to the production of a toolkit (DfT, 2011c). Our starting point, and one that underpins the BCR calculations in section 4, is a microeconomic approach that relates to the rational choices model. Although this approach can be adequate for explaining aggregate policy responses, it is less useful in explaining individual behaviour. The emerging field of behavioural economics has highlighted issues surrounding loss aversion, 'short-termism', procrastination, overestimation of small probabilities and bounded rationality. It has shown how small adjustments to choice architectures can lead to large changes in behavioural change - the basis of the nudge hypothesis (Thaler and Sunstein, 2009). Psychological models such as those associated with Ajzen (1991) and Triandis (1977) emphasise the role of attitudes, social norms, perceived behavioural control, beliefs, emotions and habit and can highlight the disconnect between intentions and behaviour. Attitude Behaviour Context (ABC) models also emphasise the role of environmental factors (Stern, 2000). Social practice approaches highlight the interplay 
between the individual (skills), the social (images and meaning) and the material (things) (Hargreaves, 2011). Although these developments may seem to be only of academic relevance, they are affecting policy and contributing to the greater emphasis on the lower rungs of the ladder of interventions.

\section{RECENT DEVELOPMENTS IN THE UK AND THE EU}

Recent developments in the UK have focussed on local delivery of sustainable transport, by decentralising economic power (through the creation of Local Enterprise Partnerships and the development of Tax Increment Financing) and land use planning by introducing competition for Local Sustainable Transport Funds (LSTF) (DfT, 2011a). Winning LSTF bids focus on a package of hard and soft measures to achieve behavioural change. For example, Southampton City Council's successful LSTF bid combines 'hard' physical measures to improve the provision for active travel and public transport with 'softer' measures related to targeted marketing, including personalised travel planning and corporate travel plans (covering workplaces, schools and transport termini). This is an attempt to use the range of approaches identified in the ladder of interventions.

The most recent EC Transport White Paper, also published in 2011 (EC, 2011) focuses on longer distance supranational transport with an emphasis on freight as well as passenger transport. Of the ten goals for a competitive and resource efficient transport system (and there is a concern that the overall aim neglects the social), some five might be seen to directly relate to transport integration. Four goals are related to optimising the performance of multimodal logistic chains, including targets for modal shift for freight movements greater than $300 \mathrm{~km}$, completion of a High Speed Rail network and targets for rail's share of medium distance transport, development of a TEN-T core network and plans to connect all core airports and seaports to the rail network. There is also a goal to establish a framework for a European multimodal transport information, management and payment system. The focus seems to remain on the upper rungs of the ladder of intervention. Of the 40 initiative identified in the Annex, some 29 are predominantly related to regulation of some form or another, five are broadly economic (pricing and funding), two relate to physical infrastructure and four relate to information (travel, carbon footprinting, vehicle labelling and eco-driving). The main tool for achieving integrated urban mobility seems to be a proposal for mandatory Urban Mobility Plans and Audits. Overall, the emphasis seems to remain on physical measures - the cost of EU infrastructure development to meet transport demand has been estimated to be $€ 1.5$ trillion for 2010-30. The era of predict and provide does not yet seem to be over in Europe. 


\section{CONCLUSIONS}

The progress towards seamless and integrated transport has not been smooth. Potter (2010) notes that the short-term, non strategic model of competition adopted in the UK inherently acts against integration. A similar conclusion is reached by SchöllerSchwedes (2010) for the EU where it is argued that the political idea of cooperation has been overwhelmed by the economic dominance of competition. Pan (2011) notes how progress towards seamless mobility in Shanghai has been hampered by the commercialisation of bus operations and how the tensions between commercial and social objectives are highlighted in an economic downturn. Reduced subsidies have led to higher fares, whilst the increased imperative of economic development leads to the relaxation of planning restrictions. These are phenomena that have global applicability.

However, this paper has shown that an empirical database is emerging at a European scale concerning the beneficial elements of integrated transport policy, in particular concerning the benefits of reducing car dependency. Improvements to public transport can be shown to be beneficial in terms of a narrow definition of costs and benefits and the case for such improvements may be strengthened where wider social, economic and environmental effects are taken into account. Schemes which have a particular focus on integration across modes may have particularly good returns. Although the precise numbers of much of the evidence presented can be disputed, a relatively uniform picture emerges that transport integration measures can represent good value for money in benefit cost terms and can lead to substantial reductions in car travel. This in turn suggests that current levels of integration are sub-optimal and that the implementation of integration measures would generally be beneficial.

In Preston (2010a) detailed recommendations for progressing integrated transport were identified. These have been reviewed in the light of the additional evidence presented here and some of key message are summarised with respect to short term, medium term and long term measures. Some overall conclusions are then provided.

\subsection{Short term measures}

Recent evidence in the UK suggests quick wins in the short run may be achieved by policy packages that focus on both the lower rung of the integration and the intervention ladders. This includes the promotion of active travel (walking and cycling) and public transport and the roll out individualised marketing and travel planning programmes. The Smarter Choices agenda (section 4.3.2) is a key component of integrated transport and should, along with complementary physical and pricing measures, be pursued with increased vigour. There is a possibility that for a significant group of travellers more sustainable forms of transport could become the default mode, particularly for shorter trips. 
The evidence also suggests that public transport (and particularly bus) could play a much greater role in the short run. Public transport trips per head are around 430 in London (including rail) but are only around 110 in the six English PTEs. For urban areas such as Brighton, Edinburgh, Nottingham and Reading a range of 140-190 trips per head is found (White, 2008, 15-16). In regional centres in France a range of 100 to 180 is found, whilst in Germany a range of 250 to 380 can be found (Hass-Klau et al., 2007).

However, the evidence also indicates that competition in the market cannot deliver integrated transport. Integration can though be delivered if bus operations are procured by competitive tender (competition for the market), and there are benefits if this takes place at a route rather than an area level and at frequent intervals, except where substantial capital investment is required (Preston, 2005). Whilst, it is appropriate that strategic functions are provided by public authorities, the allocation of tactical functions associated with network planning is problematic, as ideally this would involve input from both authorities and operators. Methods of contracting out the tactical function of planning public transport networks to third party providers might be usefully considered (Preston, 2007).

Public transport fares and ticketing might also be reviewed. Commercial systems may result in fares that are too high and ticketing that is too complex. Conversely, public intervention may result in overly simple ticketing, such as the low flat fare in Beijing (Pan, 2011) and the free concessionary travel in the UK (Preston, 2008). Instead, variants of the highly successful network cards in Germany and Switzerland might be considered (Fitzroy and Smith, 1994, 1998).

\subsection{Medium-term measures}

In certain circumstances, the evidence also indicates that new urban rail schemes have a role to play. However, given the longer planning cycles, infrastructure improvements can only be delivered in the medium term. The wider development of Sbahn style electrified suburban services might be considered along with the physical integration of local rail with other modes including the implementation of the tram/train technologies that have been developed in cities such as Kassel and Karlsruhe in Germany (Axhausen and Brandl, 1999).

Medium term measures might also focus on the middle rungs of the integration ladder. Particular emphasis should be placed on pricing integration, so that both public and private transport have pay-as-you-go charging that reflects marginal costs, a long standing aspiration of the EC. Global Positioning Systems, Direct Short Range Communications, Smartcards and mobile phones may provide technological platforms for such integration, although developments seem to be driven by the private sector more than Governments. The application of information technology should be encouraged, for example through funding for demonstration projects as it offers further possibilities for transport integration, including pervasive, multi-modal, real-time information and navigation and the development of bespoke services such as demand responsive transport and lift sharing. However, as Smartcards, such as Oyster in London, have illustrated there are challenges in ensuring that these technologies are interoperable which can only be met with the development of bodies such as the UK's ITSO (the Integrated Transport Smartcard Organisation). At the same time, contactless bank cards have been developed by the major high street banks for small transactions and appear 
poised to take over from smart cards as a potentially universally interoperable system of payment for public transport (ITF/KOTI, 2012).

\subsection{Long-term measures}

Longer term wins might involve the top-rungs of the integration ladder and will involve changes in governance structures and policy practice to encourage 'joined up' government. However, it is likely that such ways of working can not be readily prescribed but will require flexible arrangements such as cross Departmental working parties. In the words of Van de Velde: "As optimal coordination is a moving target, owing to technical and social changes, the institutional design should be flexible enough to accommodate future needs without repeated legal changes" (Van de Velde, 2005, 133). Megaprojects, such as High Speed Rail, have long planning horizons. It is tempting, in order to speed up delivery, to develop a special agency for that purpose (such as HS2 Ltd in the UK) but this can come at the expense of wider integration.

Integrated policy appraisal across sectors should be developed at a strategic level with an emphasis on the key economic, social and environmental objectives. For example, decisions to centralise health care facilities or introduce competition into the education sector should include a revised and streamlined NATA style appraisal that includes impacts on the transport system. However, at the same time an overly detailed and burdensome appraisal process should be avoided as this could contribute to paralysis by analysis.

NEA et al. (2003) have suggested that implementation may be assisted by city authorities adopting an integration contract (including an integrated network statement), which users can then hold them accountable for with regular progress reports and clear key performance indicators (KPIs). This has similarities with the EU's suggestions for Mobility Plans and Audits and such measures will also allow yardstick competition as cities can be easily compared with respect to the degree of integration they have achieved.

\subsection{Final Comments}

We have shown that workable definitions of integrated transport now exist. Substantial evidence on operationalizing the concept and on appraising and evaluating the results of integrated policy initiatives also now exists, although further systematic review is required. Advances in the social sciences have given some insight into how policy can be framed to overcome individual barriers to behavioural change. Smarter choices have emerged as an important policy development in integrated transport particularly with respect to progress on the lower rungs of the ladders of integration and intervention. However, important institutional barriers inhibit progress on the upper rungs of the integration ladder and these will only be overcome with carefully crafted intervention to ensure adequate coordination as transport markets are opened to competition. However, with a combination of these bottom-up and top-down approaches, there seems a possibility that integrated transport can scale new heights. 


\section{BIBLIOGRAPHY}

Ajzen, I. (1991). The Theory of Planned Behavior. Organizational Behavior and Human Decision Processes, 50, 179-211.

Allen, J., Browne, M. and Woodburn, A. (2010) Integrated Transport Policy in Freight Transport. In Givoni, M. and Banister, D. (Eds) Integrated Transport: From Policy to Practice. Routledge, Abingdon. 75-96.

Anderton, K. (2010) The Need for Integrated Institutions and Organisations in Transport Policy. In Givoni, M. and Banister, D. (Eds) Integrated Transport: From Policy to Practice. Routledge, Abingdon. 55-74.

Axhausen, K.W. and P.G. Brandl (1999) The Dynamics of LRT growth: the case of Karlsruhe since 1975. Transport Reviews, 19 (3) 221-240.

Bae, S. (2010) Policy Measures to Simulate Intermodal Transportation in High Speed Networks. MSc Dissertation, School of Civil Engineering and the Environment, University of Southampton.

Bakker, P., Koopmans, C. and Nijkamp, P. (2010) The Appraisal of Integrated Transport Policies. In Givoni, M. and Banister, D. (Eds) Integrated Transport: From Policy to Practice. Routledge, Abingdon. 117-136.

Barker, K. (2006). Barker Review of Land Use Planning. Final Report Recommendations. HMSO, London.

Button, K.J. (1993) Transport Economics. $2^{\text {nd }}$ Edition. Edward Elgar, Cheltenham.

Cairns, S., Sloman, L., Newson, C., Anable, J., Kirkbride, A. \& Goodwin, P. (2004) Smarter Choices - Changing the Way We Travel. Chapter 6: Public Transport Information and Marketing. HMSO, London.

CEC (Commission of the European Communities) (1985) Completing the Internal Market. COM 85 (310). CEC, Brussels.

CEC (2001) European Transport Policy for 2010: time to decide. COM(2001)370. CEC, Brussels.

CEC (2006) Keep Europe Moving - Sustainable Mobility for our Continent. Mid-term review of the European Commission's 2001 Transport White Paper. COM(2006)314. CEC, Brussels.

Cm 3234 (1996) Transport: The Way Forward. The Government's response to the transport debate. HMSO, London. 
Cottham, G.W. (1985) The cost effectiveness of integrated public transport: West Yorkshire - a case study. Metro. West Yorkshire Passenger Transport Executive, Wakefield.

Cresswell, R. (Ed) (1979) Urban Planning and Public Transport. Construction Press, Lancaster

DETR (Department of Environment, Transport and the Regions) (1998) A New Deal for Transport: Better for everyone. HMSO, London.

DETR (2000a). Transport 2010 - The Ten Year Plan. HMSO, London

DETR (2000b) Guidance on the Methodology for Multi-Modal Studies (GOMMMS). DETR, London.

DfT (Department for Transport) (2004). The Future of Transport: a network for 2030. HMSO, London.

DFT (2009a) Delivering a Sustainable Transport System. DfT, London.

DfT (2009b) NATA Refresh. Appraisal for a Sustainable Transport System. DfT, London.

DfT (2011a) Creating Growth, Cutting Carbon. Making Sustainable Local Transport Happen. January. DfT, London.

DfT (2011b) The Transport Business Case. April. DfT, London.

DfT (2011c) Behavioural Insights Toolkit. November. Social Research and Evaluation Division. DfT, London.

Docherty, I. and Shaw, J. (Eds) (2003) A New deal for transport? The UK's struggle with the sustainable transport agenda. Blackwell, Oxford .

Docherty, I and Shaw, J. (Eds) (2008) Traffic Jam: 10 years of 'sustainable' transport in the UK. The Policy Press, Bristol.

Dodgson, J. (2009) Rates of Return on Public Spending on Transport. RAC Foundation Report 09/103. RAC Foundation, London.

EC (European Commission) (1992) The Future Development of the Common Transport Policy - A Global Approach to the Construction of a Community Framework for Sustainable Mobility. EC, Brussels.

EC (2011) White Paper. Roadmap to a Single European Transport Area - Towards a competitive and resource efficient transport system. COM(2011) 144. EC, Brussels.

Eddington, R. (2006). The Eddington Transport Study. Main report: Transport's role in sustaining the UK's productivity and competitiveness. HMSO, London

Evans, A. (1987) A Theoretical Comparison of Competition with Other Economic Regimes. Journal of Transport Economics and Policy, 21, 7-36. 
Fitzroy, F. and Smith, I. (1994) The demand for public transport: some estimates from Zurich. International Journal of Transport Economics, 21, 2, 197-207.

Fitzroy, F. and Smith, I, (1998) Public transport demand in Freiburg: why did patronage double in a decade? Transport Policy, 5, 3, 163-173.

George, C. (2001) Sustainability appraisal for sustainable development: integrating everything from jobs to climate change. Impact Assessment and Project Appraisal. $19,2,95-106$.

Givoni, M. and Banister, D. (Eds) (2010) Integrated Transport: From Policy to Practice. Routledge, Abingdon.

Gladwell, M. (2000) The Tipping Point: How little things can make a big difference. Little Brown, London.

Glaister, S. (2001) The Economic Assessment of Local Transport Subsidies in Large Cities. In Grayling, T. (Ed) Any More Fares? IPPR, London.

Glaister, S. (2002) UK transport policy 1997-2001. Oxford Review of Economic Policy, 18, 2, 154-186.

Goodwin, P.B., Hallett, S., Kenny, F. and Stokes, G. (1991) Transport: The new realism. Reference 624, Transport Studies Unit, University of Oxford.

Goodwin, P. (2003) Towards a genuinely sustainable transport agenda for the United Kingdom. In Docherty and Shaw (eds) A New deal for transport? The UK's struggle with the sustainable transport agenda. Blackwell, Oxford.

Hargreaves, T. (2011) Practice-ing Behaviour Change: Applying social practice theory to pro-environmental behaviour change. Journal of Consumer Culture, 11, 1, 79-99.

Hass-Klau, C., Crampton, G. and Ferlic, A. (2007) The Effect of Public Transport Investment on Car Ownership: the results for 17 urban areas in France, Germany, UK and North America. ETP, Brighton.

Hibbs, J. (2000) Transport Policy: The Myth of Integrated Planning. Institute of Economic Affairs, London.

Huang, B. and Preston, J. (2004) Welfare Maximising Configuration of Urban Bus Market. European Transport Conference, Strasbourg.

Hull, A. (2005) Integrated Transport Planning in the UK: From concept to reality. Journal of Transport Geography, 13, 318-328.

IHT (The Institution of Highways and Transportation) (2009) Making Smarter Choices. IHT, London.

ITF/KOTI 2012, Seamless Public Transport for All, ITF Policy Brief April and Proceedings of Joint Seminar, forthcoming. OECD, Paris.

MacKinnon, D., Shaw, J. and Docherty, I. (2008). Diverging Mobilities, Devolution, transport and policy innovation. Elsevier Science, Oxford. 
May, A.D. (2001) Development of an International Knowledgebase on Urban Transport Policy Instruments. Proceedings of the $9^{\text {th }}$ World Conference on Transport Research. Korea Transport Institute/Korea Society of Transportation, Seoul.

May, A.D., Kelly, C. and Shepherd, S. (2005a) Integrated Transport Strategies. In Button, K.J. and Hensher, D.A. (Eds) Handbook of Transport Strategy, Policy and Institutions. Elsevier, Oxford. 237-254.

May, A.D., Shepherd, S. and Emberger, G. (2005b) Optimization of Transport Strategies. In Button, K.J. and Hensher, D.A. (Eds) Handbook of Transport Strategy, Policy and Institutions. Elsevier, Oxford. 665 -684.

May, T and Crass, M. (2007) Sustainability in Transport: Implications for Policy Makers. Transportation Research Record, 2017, 1-9.

Mayeres, I, Proost, S., Emberger, G., Grant-Muller, S., Kelly, C. and May, A.D. (2003) Synergies and Conflicts of Transport Policies. SPECTRUM Deliverable D4. Institute for Transport Studies, University of Leeds.

Mohring, H. (1972) Optimisation and Scale Economies in Urban Bus Transportation. American Economic Review, 62, 591-604.

MVA (2004) Integration of Regional Transport Strategies with Spatial Planning Policies. DfT, London.

Nash, C.A. (1988) Integration of Public Transport: An Assessment. In Dodgson, J. and Topham, N. (Ed) Bus Deregulation and Privatisation. Gower, Aldershot.

Nash, C. and Preston, J. (1991) Appraisal of Rail Investment Projects: Recent British Experience. Transport Reviews, 11, 4, 295-309.

NEA, OGM and TSU (2003) Integration and Regulatory Structures in Public Transport. Final Report. DGTREN, Brussels.

Pan, H., 2011 Implementing Sustainable Urban Travel Policies in China International Transport Forum Discussion Paper No 2011-12, May. OECD, Paris.

Pearce, D., Markandya, A. and Barbier, E. (1989) Blueprint for a Green Economy. Earthscan, London.

Piao, J., Preston, J., McDonald, M. and Hall, R. (2009) Cost Benefit Analysis Report. CIVITAS GUARD Project. Transportation Research Group, University of Southampton.

Potter, S. and Skinner, M.J. (2000). On transport integration: a contribution to better understanding. Futures, 32, 275-287.

Potter, S. (2010) Transport Integration - an impossible dream? Universities Transport Study Group Annual Conference. University of Plymouth.

Preston, J., Whelan, G. and Wardman, M. (1999) An Analysis of the Potential for Ontrack Competition in the British Passenger Rail Industry. Journal of Transport Economics and Policy, 33, 1, 77-94. 
Preston, J. and Spear, J. (2008) Transport Governance and City Regions: The Case of Rail RGS/IBG Annual Conference. Imperial College London.

Preston, J. (2005) Tendering of Services. In Button, K. and Hensher, D. (Eds) Handbook of Transport Strategy, Policy and Institutions. Elsevier, Oxford. 65-82.

Preston, J. (2007) Contracting-Out Public Transport Planning: Prospects and Options. In Macario, R. (Ed) Competition and Ownership in Land Passenger Transport : Selected papers from the 9th International Conference (Thredbo 9). Chapter 11. Elsevier, Oxford.

Preston, J. (2008) Public Transport Subsidisation. In Ison, S. and Rye, T. (Eds) The Implementation and Effectiveness of Transport Demand Management measures: An International Perspective. Ashgate, Aldershot.

Preston, J. (2010a) What's so funny about peace, love and transport integration? Research in Transport Economics, 29, 329-338.

Preston, J (2010b) Measuring the Costs and Benefits of Integrated Transport Policies and Schemes. In Givoni, M. and Banister, D. (Eds) Integrated Transport: From Policy to Practice. Routledge, Abingdon. 207-222.

Preston, J. (2012) High Speed Rail in Britain: About time or a waste of time? Journal of Transport Geography. Forthcoming.

Prochaska, J. O. and Di Clemente, C. C, (1983) Stages and processes in self-change of smoking: towards an integrative model of behaviour change. Journal of Consulting and Clinical Psychology, 51, 390-5.

Rogers, R. (1999) Towards an Urban Renaissance. E\&FN Spon, London. 87-109.

Roumboutsos, A. and Kapros, S. (2008). A game theory approach to urban public transport integration. Transport Policy, 15, 4, 209-215.

Rye, T. (2008) Mind the Gap. The UK's record in European perspective. In Docherty, I and Shaw, J (Eds) (2008) Traffic Jam: 10 years of 'sustainable' transport in the UK. The Policy Press, Bristol.

Schöller-Schwedes, O. (2010) The Failure of Integrated Transport Policy in Germany: A historical perspective. Journal of Transport Geography. 18, 1, 85-96.

Sloman, L. (2003). Less traffic where people live: how local transport schemes can help cut traffic. Transport for Quality of Life and Transport 2000, London.

Sloman, L., Cairns, S., Newson, C., Anable, J., Pridmore, A. and Goodwin, P. (2010) The Effects of Smarter Choice Programmes in the Sustainable Travel Towns. Department for Transport, London.

Smarter Travel Sutton (2009) Lesson Learnt in the Delivery of a Behaviour Change Programme. Transport for London, London.

Smarter Travel Sutton (2010) Third Annual Report. Transport for London, London. 
Stern, P (2000). Towards a Coherent Theory of Environmentally Significant Behaviour. Journal of Social Issues 56 (3), 407-424.

Stradling, S., Meadows, M.L. and Beatty, S. (2000) Helping drivers out of their cars. Integrating transport policy and social psychology for social change. Transport Policy, 7, 3, 283-292.

TAPESTRY (2003) Recommendations and Results. Deliverable 6. Annex A. Check Lists for Local Policy Makers and Practitioners. Contract no. 2000-RD 10988.

Thaler, R. and Sunstein, C. (2009) Nudge: Improving Decisions About Health, Wealth, and Happiness. Penguin, London.

Triandis, H. (1977). Interpersonal Behaviour. Brookes/Cole, Monterey, California.

Van de Velde, D.M. (2005) Co-ordination, integration and transport regulation. . In Button, K.J. and Hensher, D.A. (Eds) Handbook of Transport Strategy, Policy and Institutions. Elsevier, Oxford. 115-134.

van Nes, R. (2002). Design of multimodal transport networks: A hierarchical approach. TRAIL-Thesis Series T2002/5. TRAIL Research School, DUP Science, The Netherlands.

van Reeven, P. (2003) Competition in Scheduled Transport. PhD Thesis. Erasmus University, Rotterdam.

White, P.R. (2008) Factors Affecting the Decline of Bus Use in the Metropolitan Areas. PTEG, Leeds. April.

Wootton, J. and Marsden, G. (2001) The Local Transport Plan Submissions. Transportation Research Group, University of Southampton. 
